\title{
Dissolution of a Nigerian sourced Muscovite ore for use as an ingredient in paint production
}

\author{
Daud T. Olaoluwa ${ }^{\mathrm{a}, *}$, Abdulhadi E. Abdulmalik ${ }^{\mathrm{a}}$, Taoreed A. Muraina ${ }^{\mathrm{a}}$, Sadisu Girigisu ${ }^{\mathrm{b}}$, Ayo F. \\ Balogun ${ }^{\mathrm{c}}$
}

\author{
${ }^{a}$ Department of Science Laboratory Technology, The Federal Polytechnic, P.M.B. 231, Ede, Nigeria. \\ ${ }^{b}$ Department of Science Laboratory Technology, The Federal Polytechnic, P.M.B. 420, Offa, Nigeria \\ ${ }^{c}$ Department of Chemistry, Kogi State College of Education (Technical), Kabba. P.M.B. 242, Nigeria
}

\begin{abstract}
Dissolution and characterization studies on the purification of muscovite ore in hydrochloric acid for use in paint production was investigated. Specific dissolution parameters including the effects of acid concentration as well as temperature on the dissolution of muscovite ore were studied. Important instrumentation techniques such as X-ray Fluorescence (XRF), X-ray Diffraction (XRD) and Scanning Electron Microscopy (SEM) were employed for the better explanation of the dissolution process so as to fathom the availability of elements and compounds within the ore. The results revealed that the dissolution rates were considerably influenced as the acid concentration and temperature increased, while at optimal leaching conditions, about $85 \%$ of the ore was found to have been reacted by $2.5 \mathrm{~mol} / \mathrm{L}$ at $75^{\circ} \mathrm{C}$ temperature and at 120 minutes of leaching time. The reaction order for the dissolution can be deduced to be half order reaction as the value obtained was in the bracket of 0.50 . The reaction kinetic data revealed the dissolution mechanism to involve diffusion and surface chemical mechanisms as the rate controlling mechanisms while the different instrumentation techniques corroborated the dissolution as well as purification of the muscovite ore as an ingredient for possible use in paint production.
\end{abstract}

Keywords: Characterization, diffusion, dissolution kinetics, hydrochloric acid, leaching, muscovite ore.

Article History :

Received: 17 April 2020

Received in revised form: 09 May 2020

Accepted for publication: 09 June 2020

Published: 01 August 2020

(C)2020 Journal of the Nigerian Society of Physical Sciences. All rights reserved. Communicated by: W. A. Yahya

\section{Introduction}

Muscovite with the chemical formula $\mathrm{KAl}_{2}\left(\mathrm{AlSi}_{3} \mathrm{O}_{10}\right)(\mathrm{OH})_{2}$, is an important mineral amongst the mica group that is characterized by layered crystal structure, a density range of 2.77 to $2.88 \mathrm{~g} / \mathrm{cm}^{3}$ and majorly described predominantly as of metamorphic origin but also found in igneous and sedimentary rocks as a light coloured phyllosilicate [1]. It is made up of paral-

\footnotetext{
${ }^{*}$ Corresponding author tel. no: +2348032064189

Email address: daudolaoluwa@gmail . com (Daud T. Olaoluwa )
}

lel sheets of silicate tetrahedrons that are weakly bonded together by a layer of potassium ions [2]. These sheets are characterized as being chemically inactive, water absorbing, prevents loss of heat, flexible, dielectric, lightweight, reflective, resilient, refractive, transparent to opaque and stable when exposed to water, electricity, light and extreme temperatures. As a result of these its superior electrical properties as well as its abundance, muscovite has been employed as the major mica used by industries as insulation materials in high voltage and high power electrical machines, electronic instruments, water 
columns, condensers and radio tubes, high-duty boilers and in other industrial products and instruments as well as its extensive use as a pigment extender in paints where it serves purposes such as; chalking reduction, water penetration and weathering reduction, tone of coloured pigments brightener, sustains pigments in suspension as well as in the reduction of shrinking and shearing of the finished surfaces $[3,4,5]$.

Muscovite, despite its high density is still not readily and easily separated from quartz using heavy liquids as a result of its high surface energy [6] which allows it float and also as a result of the presence of elements such as aluminium, potassium, iron and titanium etc. which serves as impurities and could apparently reduce the quality of the muscovite $[7,8]$. Muscovite ore processing methods mainly include shape separation; a method where particles are separated based on shapes required for the improvement in quality of powder products, pneumatic separation; using aerodynamics properties of particles to heave light, dusty and husky materials out of grains while heavier materials settle, and flotation; a process for selectively separating hydrophobic materials from hydrophilic substances $[9,10,11,12]$. Purification studies of muscovite involves fluoric acid leaching which has been found to show great effects on processing of muscovite but also found to lead to severe environmental pollution [13, 14]. Other purification studies such as the oxygen pressure acid leaching involves high acid consumption and an elongated leaching or reaction time which ends up leading to consequential declines in equipment life, production output as well as raise in production costs $[15,16]$. Therefore, this research sets out to determine the purification activities of muscovite ore in hydrochloric acid while critically examining the effects and extents acid concentrations, reaction temperature and particle size might have on the ore dissolution for better interpretation of the optimal purification process as well as its possible use as a pigment extender in paint production.

\section{Materials and methods}

For this study, the muscovite sample was sourced from Mangu Local Government Area of Plateau State, Nigeria and the sample was crushed and milled to yield a fine powder and then sifted into different particle mesh sizes $(53 \mu \mathrm{m}, 63 \mu \mathrm{m}$ and $90 \mu m$ ) using the American Society for Testing and Materials (ASTM) standard sieve fractions, with the size fraction with the largest surface area used for characterization and leaching studies.

The EMPYREAN X-ray diffractometer equipped with a Bruter X-Flash detector using Esprit 1.82 software X-ray Diffraction Spectroscopy (XRD) was employed in determining the material purity assessment as well as to identify compounds of in- terest present in the ore sample while the MINI PAL 4 EDXRF spectrometer was used in determining the elemental composition of the muscovite sample. The samples were carbon coated and viewed at $5.0 \mathrm{kV}, 26 \mathrm{~mm}$ working distance using SEM model Vega3 TESCAN with LaB6 filament to study the structural morphology of the ore sample. Physicochemical parameters such as moisture content, loss of mass on ignition as well as the surface $\mathrm{pH}$ of the raw ore were adequately appraised using standard procedures.

\subsection{Leaching Process}

Acid dissolution experiments was carried out in a $250 \mathrm{ml}$ glass beaker erected on a hot plate with automatic temperature control and magnetically stirred for 120 minutes. The setup was equipped with a watch glass on the beaker to avoid evaporation, thereby, enabling the condensation of the leach solution. Dissolution parameters including hydrochloric acid $(\mathrm{HCl})$ concentration and leaching temperatures were studied to ascertain the optimum leaching conditions. Known concentrations of acid solutions were prepared and placed in the glass beaker till the solution reached the desired temperature, then the ore sample was introduced into the beaker and magnetically stirred as the dissolution proceeded. The amount of ore sample introduced for the reaction/dissolution was weighed to make up a pulp of $10 \mathrm{~g} / \mathrm{L}$. The residue after leaching was filtered, washed, dried and weighed and the fraction of the ore reacted was calculated from the initial difference in weight of amount dissolved and undissolved at various time intervals. Appropriate kinetic curve was examined using the established shrinking core models for the establishment of the dissolution mechanism while selected residues after appropriate treatments were fully characterized by SEM and XRF [16].

\section{Results and Discussion}

The elemental composition (Table 1) of the raw muscovite ore sample by EDXRF and confirmed by XRD spectrum shows that the ore contains Silicon, Aluminium, Potassium, Rubidium and Tin, occurring as major elements while other elements such as Calcium, Phosphorus, Manganese, Iron, Nickel, Copper, Zinc, and Molybdenum occur from low to trace levels ( $\leq$ $0.5 \%$ ). The XRD pattern (Figure 1) as shown confirms the raw ore sample to be predominantly muscovite, although with traces of albite and quartz.

The XRD also gave the formulas of each of these components as muscovite $\left(\mathrm{K}_{3.60} \mathrm{Na}_{0.28} \mathrm{Al}_{9.60} \mathrm{Fe}_{0.88} \mathrm{Mg}_{0.66} \mathrm{Ti}_{0.08} \mathrm{Si}_{2.80}\right.$ $\left.\mathrm{O}_{48.00} \mathrm{H}_{8.00}\right)$, albite $\left(\mathrm{Na}_{2.60} \mathrm{Al}_{2.00} \mathrm{Si}_{6.00} \mathrm{O}_{16.00}\right)$ and quartz $\left(\mathrm{Si}_{3.00} \mathrm{O}_{6.00}\right)$.

The scanning electron image (SEI) at different magnifications to investigate the structural morphology of the raw muscovite ore samples is as shown in Figure 2 and it was observed that 


\begin{tabular}{ccccccccccccccc} 
Elements & $\mathrm{Si}$ & $\mathrm{Al}$ & $\mathrm{K}$ & $\mathrm{Rb}$ & $\mathrm{Sn}$ & $\mathrm{S}$ & $\mathrm{Ca}$ & $\mathrm{P}$ & $\mathrm{Mn}$ & $\mathrm{Fe}$ & $\mathrm{Ni}$ & $\mathrm{Cu}$ & $\mathrm{Zn}$ & $\mathrm{Mo}$ \\
\hline \% composition & 10.2 & 4.2 & 9.3 & 3.55 & 1.2 & 0.54 & 0.1 & 0.22 & 0.41 & 0.43 & 0.05 & 0.05 & 0.08 & 0.22 \\
\hline
\end{tabular}

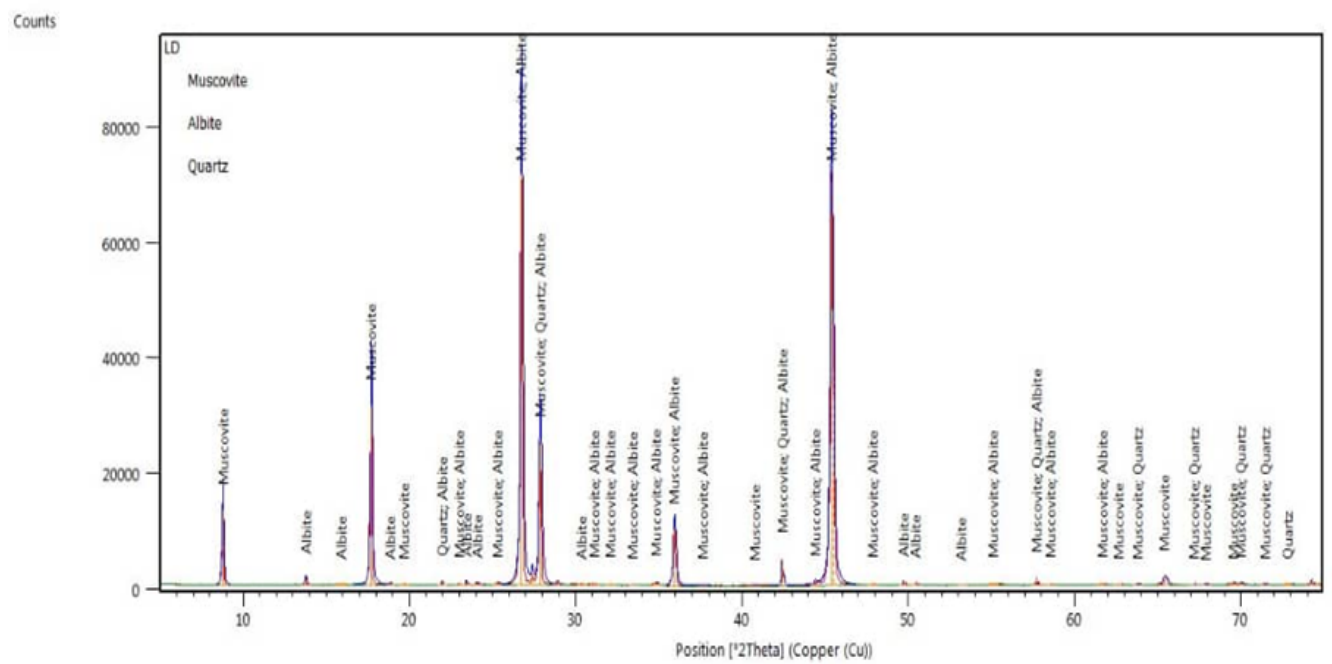

Figure 1. Identified compounds as shown by XRD with their respective Joint Committee on Powder Diffraction Standard file number for peaks assignments showing Muscovite $\left(\mathrm{K}_{3.60} \mathrm{Na}_{0.28} \mathrm{Al}_{9.60} \mathrm{Fe}_{0.88} \mathrm{Mg}_{0.66} \mathrm{Ti}_{0.08} \mathrm{Si}_{2.80} \mathrm{O}_{48.00} \mathrm{H}_{8.00}\right)$ 96-900-5188, albite $\left(\mathrm{Na}_{2.60} \mathrm{Al}_{2.00} \mathrm{Si}_{6.00} \mathrm{O}_{16.00}\right)$ 96-900-1633 and quartz ( $\left.\mathrm{Si}_{3.00} \mathrm{O}_{6.00}\right)$ 96-901-2604

throughout the wide size range of the samples, the ore particles has irregular shapes.

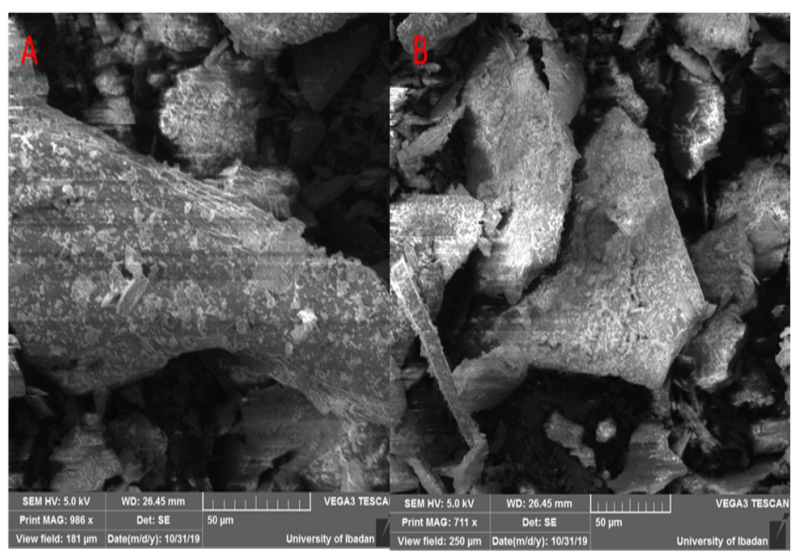

Figure 2. SEI of raw muscovite ore at different magnifications

On ignition in a muffle furnace, the ore sample and its weight was estimated and affirmed in percentages with an average LOI value of 1.5 suggesting that the organic component of the ore is just in low volume while the moisture content obtained was an average of $2.5 \%$. The $\mathrm{pH}$ range of the muscovite ore solution suspension taken in a period of five (5) days gave values between 7.35 and 7.47 with the mean $\mathrm{pH}$ being 7.42 , this affirmed that the surface of the mineral is neutral.

\subsection{Purification studies}

Extent of $\mathrm{HCl}$ concentration. Muscovite ore dissolution was carried out using $\mathrm{HCl}$ solution in the concentration range of $0.1 \mathrm{~mol} / \mathrm{L}$ to $3.0 \mathrm{~mol} / \mathrm{L}$ at $55^{\circ} \mathrm{C}$ and at different leaching times while being moderately stirred at about $300 \mathrm{rpm}$. The fraction of the ore dissolved at these different leaching times is plotted for the separate $\mathrm{HCl}$ concentrations as evidenced in Figure 3.

Figure 3 shows that as the $\mathrm{HCl}$ concentration at various leaching times increases, the rate of dissolution increases, therefore, $2.5 \mathrm{~mol} / \mathrm{L} \mathrm{HCl}$ is considered to be the optimum acid concentration and hence, for economic consideration, the optimum $\mathrm{HCl}$ concentration for this study was $2.5 \mathrm{~mol} / \mathrm{L}$ and hitherto used in the advancement of some other leaching parameters such as reaction temperature.

Effect of reaction temperature. The optimal acid concentration obtained was employed to study the extent of reaction temperature on the dissolution rate of muscovite ore dissolution over the temperature ranges of $28-75^{\circ} \mathrm{C}$ and its result is as shown in the Figure 4.

From the plot, it can be observed that the dissolution of muscovite is positively influenced as the leaching time rises at 


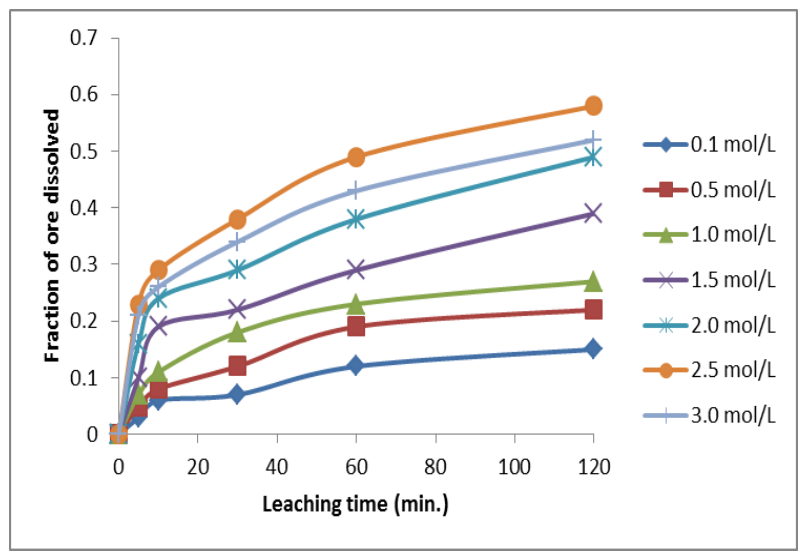

Figure 3. Extent of $\mathrm{HCl}$ concentrations on muscovite ore dissolution per different leaching time (min.). Experimental conditions: $\mathrm{HCl}$ concentration $=0.1-3.0 \mathrm{~mol} / \mathrm{L}$; Temperature $=55^{\circ} \mathrm{C}$, Particle size $=-90+53 \mu \mathrm{m}$; Solidliquid ratio $=10 \mathrm{~g} / \mathrm{L}$ with moderate stirring

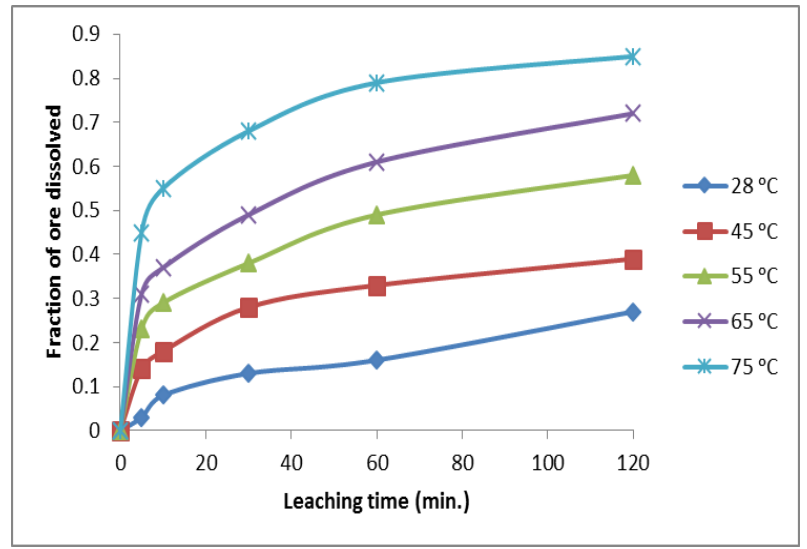

Figure 4. Extent of temperature on $\mathrm{HCl}$ muscovite ore dissolution. Experimental conditions: $\mathrm{HCl}=2.5 \mathrm{~mol} / \mathrm{L}$; Temperature $=25-75^{\circ} \mathrm{C}$, Particle size $=-90+53 \mu \mathrm{m} ;$ Solid-liquid ratio $=10 \mathrm{~g} / \mathrm{L}$ with moderate stirring

different temperature. In other words, muscovite dissolution rate is greatly affected by reaction temperature as the amount of muscovite ore leached increased at $75^{\circ} \mathrm{C}$ and 120 minutes of leaching which could be attributable to the certainty of particles reacting faster when they collide with a rapid rise in temperature.

\subsection{Dissolution kinetics analysis}

The reaction between a solid and fluid can be represented as presented in equation (1) where the rate of reaction may be controlled by either of the mechanisms namely: diffusion through fluid films, diffusion through ash/product layer, or the chemical reaction at the surface of the core of unreacted materials [17].

$$
a A(\text { fluid })+b B(\text { solid }) \rightarrow \text { Products }
$$

Data collected from leaching with various acid concentrations and at optimal dissolution conditions was used to estimate the leaching kinetics as well as the reaction order and activation energy for better understanding of the dissolution mechanisms while employing the following shrinking core models to describe the kinetic models $[18,19]$.

$$
\begin{aligned}
& 1-(1-\alpha)^{\frac{1}{3}}=k_{c} t \\
& 1-\frac{2}{3} \alpha-(1-\alpha)^{\frac{2}{3}}=k_{d} t,
\end{aligned}
$$

where $\alpha$ is the fraction reacted, $k$ is the reaction rate constant and $t$ is the leaching time. Equation (2) is used to predict the chemical reaction as the leaching rate controlling step occurring at the mineral particle surface while equation (3) predicts the diffusion through the product layer on the particle surface as the rate controlling step.

Therefore, the $\mathrm{HCl}$ solution treatment was subjected to the two aforementioned mathematical model equations. Thus, treating Figures 3 and 4 accordingly using the above kinetic equations as a function of reaction time gives a perfectly straight line for equation (3) only.

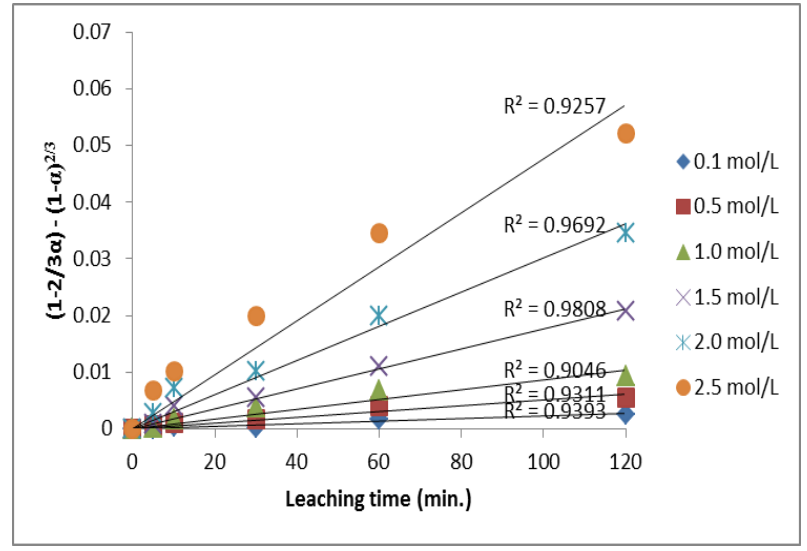

Figure 5. Plot of $1-\frac{2}{3} \alpha-(1-\alpha)^{\frac{2}{3}}$ versus leaching time at different $\mathrm{HCl}$ concentrations. Experimental conditions: Same as in Figure 3

The results of the influence of $\mathrm{HCl}$ concentration (Figure 3) were also subjected to this kinetic models with the experimental rate constant, $k_{d}$ values and correlation coefficients for each concentration evaluated. The graph of $\ln K_{d}$ versus $\ln [\mathrm{HCl}]$ was then plotted to give the reaction order of 0.4057 as presented in Figure 6.

As evidenced in Figure 6, the slope of the resulting plot estimated the reaction order to be 0.4057 with respect to $H+$ ion and a correlation coefficient of 0.9157 .

The data from Figure 4 was also linearized using equation (3) to obtain the result represented in Figure 7.

The apparent rate constant $K_{d}$ calculated from the slopes of the straight lines in Figure 7 was then used to obtain Arrhenius relation as a function of time as shown in Figure 8 below.

From the plot (Figure 8), the calculated activation energy $E_{a}$ was $53.38 \mathrm{kJmol}^{-1}$ which clearly suggests a surface chemical 


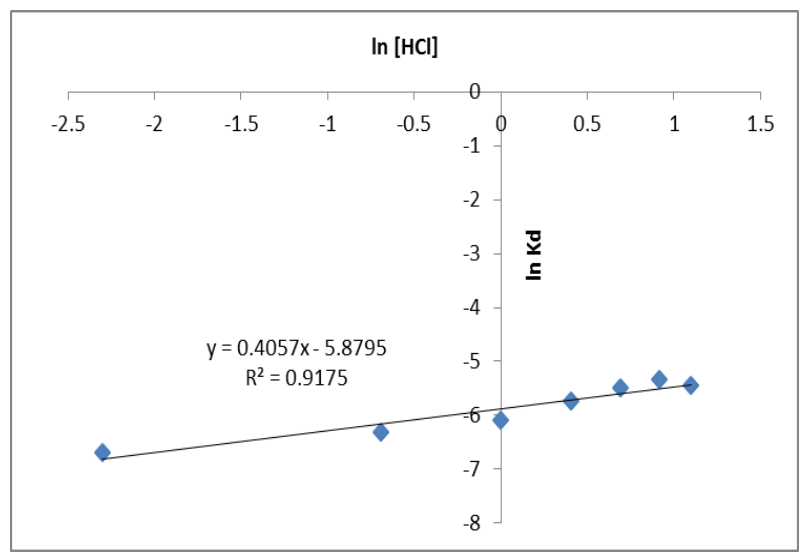

Figure 6. $\ln K_{d}$ against $\ln [\mathrm{HCl}]$

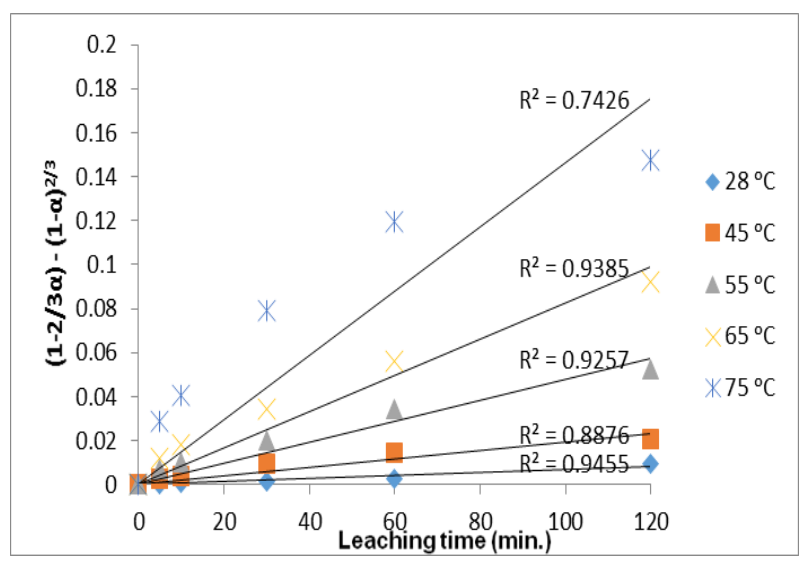

Figure 7. Plot of $1-\frac{2}{3} \alpha-(1-\alpha)^{\frac{2}{3}}$ versus reaction time at varying temperatures. Experimental conditions: Same as in Figure 4

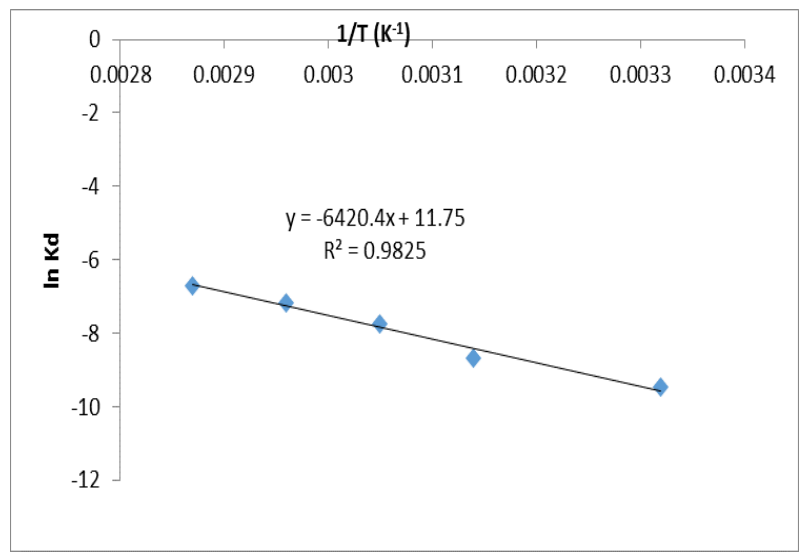

Figure $8 . \ln K_{d}$ versus $1 / T$

controlled reaction for the dissolution process as proposed by several investigators $[20,21]$. The calculated value of the activation energy obtained in the present study is above $40 \mathrm{~kJ} / \mathrm{mol}$; which supports that leaching is controlled by surface chemical mechanism, however, the high $E_{a}$ could be as a result of 2-stage mechanism which involves diffusion and surface chemical concurrently as all the subjected dissolution kinetics data gave a perfect fit for diffusion controlled mechanism.

\subsection{Residual Product Analysis}

The residual product formed after leaching at optimal conditions of $2.5 \mathrm{~mol} / \mathrm{L} \mathrm{HCl}, 75^{\circ} \mathrm{C}$ and 120 minutes of dissolution was analyzed using XRF and the result shows the presence of $5.7 \% \mathrm{Al}, 18.3 \% \mathrm{Si}, 7.8 \% \mathrm{~K}, 3.1 \% \mathrm{Rb}, 3.4 \% \mathrm{~S}$ and $0.67 \% \mathrm{Sb}$. The XRF result suggests that there was an increase in the amount of these elements as compared to the raw ore, therefore, it could be said that this process purified the muscovite ore and increased the presence of other elements which could also be used to produce these compounds.

From the SEM images of the leached muscovite ore particles presented in Figure 9 below, it can be deduced that the SEM photograph shows that the residual products were closely packed with shining surface which suggests that the ore was greatly enhanced by the hydrochloric acid processing. It also shows charged surfaces which corroborates its use in literature as a cosmetic ingredient $[4,5]$.

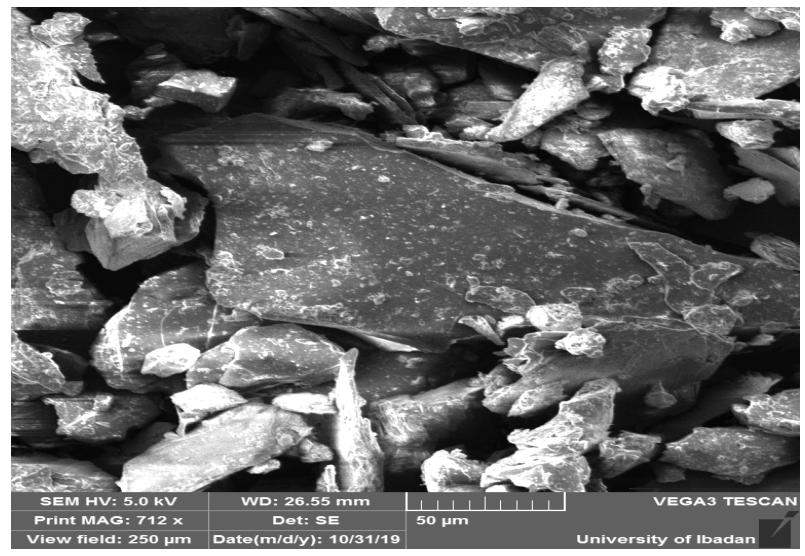

Figure 9. SEM images of $\mathrm{HCl}$ residual products

\section{Conclusion}

This research studied the dissolution of muscovite ore to obtain a high grade material which could be used as extender for paint production in acidic solution - $\mathrm{HCl}$ at a set of optimal experimental conditions of $2.5 \mathrm{~mol} / \mathrm{L} \mathrm{HCl}$ solution, within 120 minutes of agitation/dissolution and at $75^{\circ} \mathrm{C}$. The effects of solution concentrations and reaction temperatures were investigated to ascertain the level of ore dissolution while comparing the detailed characterization of the raw ore sample with the products obtained after dissolution. On this basis, these subsequent conclusions can be drawn:

- the dissolution rate increases as the leachant concentration and temperature are increased as the rate of dissolution of muscovite ore in $\mathrm{HCl}$ solution was found to enhance the ore dissolution. 
- the calculated activation energy obtained in the present study is above $40 \mathrm{~kJ} / \mathrm{mol}$; which supports the fact that the leaching process is controlled by a 2 -stage mechanism which involves diffusion and surface chemical concurrently.

- the residual product analysis by XRF and SEM confirms the purification of the ore and an increased elemental constituents in the products.

\section{References}

[1] H.-P. Blume, G.W. Brümmer, H. Fleige, R. Horn, E. Kandeler, I. Kögel-Knabner, R. Kretzschmar, K. Stahr \& B.-M. Wilke, Scheffer/schachtschabel Soil Science, Springer-Verlag, Berlin Heidelberg (2016).

[2] V. Sontevska, G. Jovanovski, P. Makreski, A. Raskovska \& B. Soptrajanov, "Minerals from Macedonia XXI, Vibrational spectroscopy as identificational tool for some phyllosilicate Minerals", Acta Chim. Slov. 55 (2008) 757.

[3] Y. Jie, Wang ling, "China Non-metallic Mining Industry", Herald, 6 (2004) 10.

[4] InfoMine Research group, "Mica (Muscovite) Market Research in the CIS" (2007).

[5] C. Chen, Y. Song, W. Li, W. Qu, L. Cai \& Y. Chen, "Study on flotation separation of muscovite and kaolinite", Advanced Materials Research, 1092-1093 (2015) 1474.

[6] S.W. Bailey, Clays and Clay Minerals: Proceedings of the Fourteenth National Conference. Elsevier Science, Berkeley, California, 456 (2013) 69.

[7] F.O. Marques, L. Burlini \& J.P. Burg, "Microstructure and mechanical properties of halite/coarse muscovite synthetic aggregates deformed in torsion”, J. Struct. Geol., 33 (2011) 624.

[8] L. Wang, R. Liu, Y. Hu, J. Liu \& W. Sun, "Adsorption behavior of mixed cationic/anionic surfactants and their depression mechanism on the flotation of quartz", Powder Technol., 302 (2016) 15.
[9] M. Panasiewicz, "Analysis of the pneumatic separation process of agricultural materials", Int. Agrophysics, 13 (1999) 233.

[10] S. Zhiqiang, S. Xinqian, F. Jifu \& Z. Weining, "Calcination factors of rubidium extraction from lowgrade muscovite ore", 4th International Symposium on High-Temperature Metallurgical Processing, Edited by: Tao Jiang, Jiann-Yang Hwang, Phillip J. Mackey, Onuralp Yucel, and Guifeng Zhou TMS (The Minerals, Metals \& Materials Society) (2013).

[11] C. Marion, A. Jordens, S. Mccarthy, T. Grammatikopoulos \& K.E. Waters, "An investigation into the flotation of muscovite with an amine collector and calcium lignin sulfonate depressant", Sep. Purif. Technol., 149 (2015) 216.

[12] A. Jordens, C. Marion, T. Grammatikopoulos \& K.E. Waters, "Understanding the effect of mineralogy on muscovite flotation using QEMSCAN", Int. J. Miner. Process., 155 (2016) 6.

[13] S.M. Lei \& Z.H. Guo, "Hazards of fluoride pollution and technical research progress of treating fluoride-containing waste water", Metal Mine, 41 (2012) 152.

[14] Z. Pei, M. Lin, Y. Liu \& S. Lei, "Dissolution behaviors of trace muscovite during pressure leaching of hydrothermal vein quartz using $\mathrm{H} 2 \mathrm{SO} 4$ and NH $4 \mathrm{Cl}$ as leaching agents", Minerals, 8 (2018) 282.

[15] N.N. Xue, Y.M. Zhang, T. Liu, J. Huang \& Q.S. Zheng, "Effects of hydration and hardening of calcium sulfate on muscovite dissolution during pressure acid leaching of black shale", J. Clean. Prod., 149 (2017) 989.

[16] A.A. Baba, D.T. Olaoluwa, A.G.F. Alabi, A.F. Balogun, A.S. Ibrahim, R.O. Sanni \& R.B. Bale, "Dissolution behaviour of a beryl ore for optimal industrial beryllium compound production", Canadian Metallurgical Quarterly, 57(2) (2018) 210.

[17] O. Levenspiel, Chemical reaction engineering, (2nd Ed.), Wiley, New York (1972).

[18] F. Habashi, Principles of Extractive Metallurgy Gordon \& Breach (1979).

[19] H. Sohn \& M. E. Wadsworth, Rate Process of Extractive Metallurgy, Plenum, New York (1979).

[20] K. Lammers, M.M. Smith \& S. A. Carroll, "Muscovite dissolution kinetics as a function of $\mathrm{pH}$ at elevated temperature", Chemical Geology 466 (2017) 149.

[21] E. H. Oelkers, J. Schott, J. M. Gauthier \& T. Herrero-Roncal, "An experimental study of the dissolution mechanism and rates of muscovite", Geochim. Cosmochim. Acta 72(20) (2008) 4948. 